\title{
A Diagnostic for Electron
}

Dynamics in Tokamaks

$$
\text { DOE/ER/ } 54166--4(12 / 97)
$$

Final Report

December 1997

Frederick Skiff and Derek Boyd

Institute for Plasma Research

University of Maryland

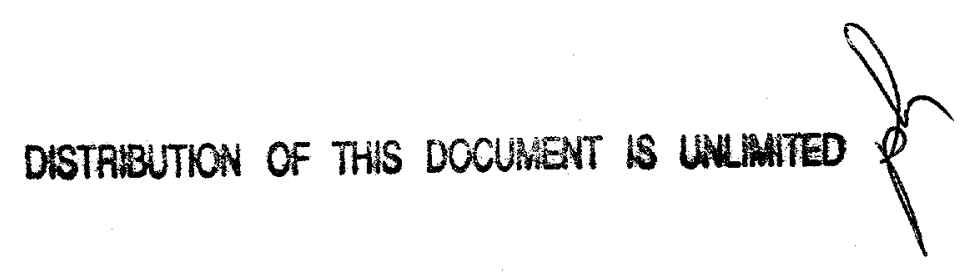




\section{DISCLAIMER}

This report was prepared as an account of work sponsored by an agency of the United States Government. Neither the United States Government nor any agency thereof, nor any of their employees, makes any warranty, express or implied, or assumes any legal liability or responsibility for the accuracy, compieteness, or usefulness of any information, apparatus, product, or process disclosed, or represents that its use would not infringe privately owned rights. Reference herein to any specific commercial product, process, or service by trade name, trademark, manufacturer, or otherwise does not necessarily constitute or imply its endorsement, recommendation, or favoring by the United States Government or any agency thereof. The views and opinions of authors expressed herein do not necessarily state or reflect those of the United States Government or any agency thereof. 


\section{DISCLAIMER}

Portions of this document may be illegible in electronic image products. Images are produced from the best available original document. 
Progress Report: The diagnostic was installed on $\mathrm{TdeV}$ and brought into operation. It was optimized to the extent that time and money permined. A considerable quantity of data was accumulated and analysed. Experiments ended in August 1995. The apparatus has been removed from TdeV and returned to the University of Maryland. Each of these activities is detailed below.

I) Installation and Decommissioning. Shipping and installation of the two chord, four channel electron cyclotron absorption (ECA) measurement system were completed in the spring of 1994. Computer controlled signal generator tamping, and signal acquisition were implemented in the same period. Experiments ceased in August 1995. The apparatus was removed in September 1995 and returned to the University of Maryland in mid 1996.

2) Transmission System. The installed system showed very good performance in vacuum, with only $3 \mathrm{db}$ loss between the transmitter and receiver homs. Eliminating the effects of waveguide dispersion on the time-domain data was achieved by using a nonlinear ramp for the control of the frequency generators. It was found that the dynamic range of the measurements was limited by the return losses from the vacuum feedthroughs and hom transitions. By increasing the asymmetry between the microwave time-of flight from the generator to the top and bottom homs, respectively, the interference due to retum losses was significantly teduced. The final system dynamic range depends on frequency, but is close to $40 \mathrm{db}$. The signal analysis was found to be very sensitive to noise on the ramp generator input. A technique was found to suppress this interference.

3) Diagnostic verification. The diagnostic was ready for participation in tokamak experiments in June of 1994 . Distribution functions measured in the first run were analyzed, discussed, and first presented at the LAEA conference in Seville. Some unexpected features were evident which caused some cuncern about the data. Repeated measurements, performed through participation in the TdeV LHCD experiments, and improvement in the dynamic range have established the existence of new phenomena. Run time of the diagnostic was limited some by a change in the plans of the TdeV operations which resulted in operation of the tokamak at higher magnetic field a signiticant portion of the time, staring in late summer 1994.

4) Participation in TdeV experiments. Paricipation in TdeV lower-hybrid experiments showed that the ECA apparatus produced the best measurements of suprathermal electron distributions that had been achieved to date. In addition to the features of these measurements which were expected, there were three features, in particular, which were not expected and which call for further snidy. These are the level of flucruations in the distriburions, the existence of electrons at energies above the resonant energy associatedwith the launched LHCD spectrum, and the magnitude and character of refractive losses.

\section{5) Results}

\section{a) Fluctuations}

The amplrude of the measured suprathermal electron distributions are observed to fluctuate in time on millisecond, or even sub-millisecond time scales at a level of 20-30\% RMS. We established that the uncertainty in the measurements thernselves is much less than $20 \%$. We conclude, therefore, that the fluctuations are real. The fluctuations are not correlated with tluctuations in refractive losses, and only rarely are correlated with the fluctuations which occur at other electron energies. The fluctuations are not correlated between the two vertical chords; therefore are not correlate in the two spatial averages of the chords. One problem we have faced is 
that such flucnations were not predicted to exist, and partially lie outside the time resolution of our current instrument. We are not aware of any theory for these fluctuations.

\section{b) High Energy Electrons}

The NII spectrum for the launched lower hybrid waves is very highly peaked. Under such conditions, it is the theoretical expectation that the energy spectrum of the suprathermal current driven electrons will be flat below the resonance energy Er(NI1), and fall off very rapidly above this energy. This is approximately what is observed on the central chord. although the distribution does not fall off as rapidly as expected above Er(NI1) and is not fully flat below Er(NI1) either. The off-axis chord indicates a almost flat distribution which at times extends to energies of, at least, three times Er(NI1).

\section{c) Spatially Hollow Distributions}

Since the off-axis thord measurements showed electron distributions extending well beyond $\mathrm{Er}(\mathrm{NI} 1)$ and the on-axis chord did not, the spatial distribution of current driven electrons is hollow ar energies above Er(NII). This occurs independently of the properties of the launched lower hybrid wave spectrim.

\section{d) Refraction effects}

We have observed that there are circumstances where the refraction losses are much greater than is predicted by ray tracing which does not include relativistic effects on the ray trajectories. This occurs even with plasma temperatures of $1 \mathrm{keV}$. Because we can isolate the effects of refraction and absorption, out data are well suited to address this issue. Unfortunately, this new effect can make it difflcult to measure absorption losses at low electron energies with the present system because the refraction losses can exceed the instrument dynamic range.

\section{e) Conclusions}

The diagnostic worked very well. Although the distribution functions behaved in ways that were not anticipated and the refractive losses were sometimes higher than projected, we were able to adapt to the unexpected. In our estimation, all of the effects listed above are significant, and warrant funther study. The diagnostic is ready for use as a tool to study the physics of current drive and current profile modification. A mechanism for steering the launched beams is desirable to cope with the strong variations in refraction which are seen. Phased atray launchers seem attractive for this purpose. Tuning of the length of the waveguide run is important to avoid troublesome reflections (retum losses). It may be best to build in this capability in a future system. The perpendicular dynamics of the current driven electrons are invisible to us with the present form of the diagnostic. Simultaneous messurements at fundamental and harmonic frequencies would make perpendicular distribution function measurements possible. 


\section{Papers Contributed at Scientific Conferences}

A) The first presentations of distribution functions obtained with the new diagnostic were presented at the Fifteenth Internatlonal Conference on Plasma Physics and Controlled Nuclear Fusion Research, Seville, Spain, 26 September- 1 October 1994 in a paper presented by R. Decoste.

Biased Divertor Performance Under LH Current Drive and Hearing Conditions on the TdeV Tokamak, R Decoste, Y. Demers, J.-L. Lachambre, B. Stansfield, G. Abel, S. Aceto, J. Beckstead, C. Boucher, D. Bourgoin, D. A. Boyd, P. Brooker, A. C8te, C. Cote, T. Fall, V. Fuchs, J.-L.Gavreau, L. Gauthier, V. Glaude, B. Gregory, S. Gulick J. Gunn, E. Haddad. P. Jacquet, J. Kalnavarns. G. Le Clair, H. H. Mai, J. Mailloux, R. Marchand, F. Martin, F. Meo, D. Michaud, R. Neufeld, D. Pinsonneault, B. Quirion, R Raman, N. Richard, G, Ross, A. Sarkissian, I. P. Shkarofsky, M. M. Shoucri, F. Skiff, M. St-Onge, B. Terreault, W. Zhang, W. Zuzak, Proceedings. IAEA- CN-601A-4-II-5.

B) $36^{\text {th }}$ APS-DPP meeting. Minneapolis MN, November 7-11 1994

Measurement of suprathermal electron distribution funcrion by extraordinary wave absorption in TdeV S. Gulick, D. Boyd, F. Skiff, R. Neufeld, D. Pinsonneault. Bull. Am. Phys. Soc. 39 pl534 (1994) Paper Is7.

Spatial Resolution of LHCD Electron Distribution Functions in the Tokamak de Varennes. D. Boyd, F. Skiff, and S. Gulick, Bull. Am. Phys. Soc. 39 pl534 (1994) Paper IsX.

Sensitivitv and Resolution of Electron Cyclotron Transmission Diagnostics. F. Skiff, D. A. Boyd, and S. Gulick, Bull, Am. Phys. Soc. 39 pl534 (1994) Paper Is9.

C) The Ninth Joint Workshop on Electron Cyclotron Emission and Electron Cyclotron Resonance Heating (EC-9), Borrego Springs, California, January 22-26, 1995.

Invited Paper Vertical View ECA. Principles and Practice. F. Skiff. D. A. Boyd, and S. Gulick. Contributed Paper ECA Dia-nosis of LHCD Distributions in the Tokamak de Varennes. D. Boyd, F. Skiff, and S. Gulick.

D) Twenty Second European Physical Society Conference on Controlled Fusion and Plasma Physics, Bournemouth, UK 2-7 July, 1995.

Lower Hvbrid Current Drive Experiments in the TdeV Tokamak, A. Cote, Y. Demers, C. Cote, R. Decoste, P. Jacquet, G. Abel, C. Boucher, D. A. Boyd, P. Brooker, V. Fuchs, J.-L. Lachambre. D. Michaud, I. P. Shkarofsky, M. M. Shoucri, F. Skiff, M. St-Onge

E) A seminar sponsored by Fusion Power Associates and the Canadian Nuclear Society. "Status and Prospects for Fusion Power Development", Montreal, Quebec, Canada. September 7-8, 1995

Title of talk: A US-Canada Collaboration D.Boyd and F. Skiff.

F) $37^{\text {th }}$ APS-DPP meeting. Louisville KY, November 6-10 1995. 
Suprathermal Electron Distribution Function Measurements during LHCD Experiments on the TdeV Tokamak. D. Boyd, F. Skiff, S. Gulick, D. Pinsonneault, A. Cote, and C. Cote

Generation and Diffusion of Suprathermal Electrons during LHCD Experiments on TdeV, C.

Cote, Y. Demers, V. Fuchs, R.A. Cairns, M. Shoucri, I. Shkarofsky, P. Brooker, Y. Peysson, J. Mailloux, D.A. Boyd, F. Skiff, A. Cote

Effect of Refraction in Rav Tracing for the Cyclotron Trasmiision Diagnoscic in TdeV. I. Shkarofsky, D. Boyd, F. Skiff, A. Kritz, G. Smith

I) Seminar: University of Maryland, College Park. MD. February 71996

Title of talk: Suprathermal Elecrron Distribution Function Measurements during LHCD Experiments on the TdeV Tokamak.

H) $11^{\text {th }}$ Topical Conference on High-Tempetature Plasma Diagnostics. Monterey CA., May 12-16 1996.

A System to Measure Suprathemal Electron Distribution Functions in Toroidal Plasmas by Electron Cyclotron Wave Absomption. D. A. Boyd, F. skiff and S. Gulick. [To be Published in Review of Scientific Insuruments]

I) Seminar ar ENEA C. E. Frascati, Italy, June 211996

Title of talk: Suprathermal Electron Distribution Function Measurements duping LHCD Experiments on the TdeV Tokamak.

D Invited talk. $23^{\text {rd }}$ European Physical society Conference on Controlled Fusion and plasma Physics. Kiev, Ukraine, June 24-28 1996.

Title of talk: Suprathermal Elecrions in Versator, Tore Supra and TdeV as seen by Electron Cuclotron Absemption Diagnostics. [To be published in Plasma Physics and Controlled Fusion]

K) $38^{\text {th }}$ APS-DPP meeting. Denver CO, November 11-15 1996

Study of LHCD physics through suprathermal electron diagnostics on TdeV. C Cote, D. Boyd, P. Brooker, M. Shoucri, V. Fuchs, I. Shkaroysky, R. A. Caims, A. Cote, Y. Demers.

Properties of LHCD Suprathermal Electron Distriburions in TdeV D. Boyd, F. Skiff, A. Cote, C. Cote, P.Brooket. 